\title{
MOBARTECH: WORKING WITH THE PUBLIC TO EXPLORE THEIR PERCEPTIONS OF MANTUA AND SABBIONETA ${ }^{1}$
}

\author{
Franca Zuccoli, Alessandra De Nicola, Alessandro Pepe \\ University of Milano-Bicocca (ITALY)
}

\begin{abstract}
This article describes a research project entitled Mobartech, a technological platform for studying and promoting historical and artistic heritage assets, co-funded by the Lombardy Region and the FSeR with the aim of stimulating industrial research, experimental development, and innovation in processes and organizations. The project comprised three case studies: an individual painting, II Quarto Stato by Pelizza da Volpedo held at Milan's Museo del Novecento; frescoes from the Giotto school in the Palazzo dell'Arcivescovado in Milan; and the cities of Mantua and Sabbioneta, which together form a single UNESCO world heritage site. We focus here on the third of these case studies, whose twin goals were to conduct scientific research on and promote the cultural heritage sites of Mantua and Sabbioneta by inviting the direct participation of members of the public. The first step in the case study was listening to the voices of the cities' users, by conducting strategic interviews on site, and developing and administering two questionnaire formats (traditional and digital) with a view to exploring tourists' and locals' relationship with the two cities and their suggestions for improving them. This article specifically examines the interview data, which told the story of the respondents' ties with Mantua and Sabbioneta, brought to light little-known aspects of the city, and informed the construction and sharing of collective knowledge at later stages of the project. The ultimate aim was to develop a toolkit for enhancing visitors' and locals' experience of the site. The kit included both physical and digital resources. The entire project was conducted within the framework of informal and inclusive education.
\end{abstract}

Keywords: Education, Mantua, Sabbioneta, Research, Public.

\section{INTRODUCTION}

The present study is part of a broader research and industrial development program entitled MOBARTECH. Una piattaforma tecnologica per lo studio e la valorizzazione del patrimonio storico artistico (MOBARTECH. A technological platform for the study and enhancement of historical-artistic heritage), conducted between 2019 and 2021.

Mobartech is a large-scale research project funded by FESR in the context of grants scheme targeting the Lombardy Region (in Northern Italy). It involves three companies, two research institutes, three universities, one museum, one place of cultural interest, and one UNESCO World Heritage Site comprising two cities. These partners have worked together towards attaining the general objectives of the program: industrial research, experimental development, and the innovation of processes and organizations. A key output of the MOBARTECH project has been the design and implementation of a mobile laboratory equipped to carry out technical-scientific analysis on cultural heritage assets that by their nature cannot be moved or are difficult to move (frescoes, monuments, architectural heritage, heritage assets that have sustained severe damage, etc.).

In sum, the research team developed and experimented with a mobile technological platform that integrates cultural, social, and creative skills and capabilities with enabling technologies, such as Information Technology, non-invasive physical technologies, image processing methods, and ad hoc transport systems for works of art.

The general objective of the platform was to innovatively support the study, conservation, dissemination and consumption of cultural heritage assets, and make them accessible to broader audiences. This was achieved by using new creative processes ("creating knowledge") to leverage cultural heritage in response to specific social needs, such as engaging the so-called non-public, who generally do not have or seek access to a variety of heritage assets. By deploying a mobile dispositive with the capacity to act simultaneously as a technical laboratory and an open lab facilitated the removal of certain barriers to accessing knowledge and culture ("Connecting people with heritage"), such as the difficulty for

\footnotetext{
${ }^{1}$ It should be noted that this paper is the result of a shared work. While the abstract was written collectively, sections 1 , was drafted by Alessandra De Nicola; sections 2, 3 were drafted by Alessandro Pepe; 4, 5 sections were written by Franca Zuccoli.
} 
audiences to physically reach heritage or to understand the study and conservation actions that maintain or increase the value of cultural assets (Developing a reflective society).

The skills and technologies made available by the MOBARTECH platform were applied in situ to perform the diagnostic analysis and restoration of artworks that are not accessible or little promoted to the public, and to deploy innovative methods of engaging the general public:

1 The insula viscontea in the centre of Milan, from the double stately residence next to the cathedral (Azzone Visconti 1330-1339, and Giovanni Visconti 1339-1354) to the former home of Bernabò Visconti in San Giovanni in Conca (1350-1385).

2 The UNESCO site of Mantua and Sabbioneta, in relation to which the municipal authorities had asked the research team to communicate to the general public the unified nature of the site and the value of world heritage site status. More specifically, Mantua City Council requested a particular focus on the Porticos of the historical city centre, the Palazzo del Podestà, and the Lungo Rio.

3 "II Quarto Stato", an oil painting on canvas by the Italian painter Giuseppe Pellizza da Volpedo, (1901) which, following a checkered history, has recently found a home at the Museo del Novecento in Milan.

In the remainder of the paper, we focus on the second of these case studies, and more specifically on the research that we conducted on locals' and visitors' perceptions of the cities of Mantua and Sabbioneta.

This case study was coordinated by a team from the Department of Human Sciences for Education at UNIMIB, in collaboration with the Mantua and Sabbioneta World Heritage Office (UNESCO). The aim was to generate goodwill among the community, leading to greater respect and care for this architectural and landscape heritage [1]. Sites that we routinely encounter in our everyday lives are not always perceived as exceptional cultural heritage. The first phase of the study consisted of collecting residents' accounts by a variety of means: a work experience project with secondary school students, experimentation in secondary schools, and participatory activities in public squares and places of culture. The second phase entailed conducting an analysis with secondary school students - two classes from a technical institute offering a tourism studies curriculum - and a representative sample of ordinary members of the public, using a battery of instruments for interpreting cultural heritage. Based on these analyses, a prototype toolkit was produced. In June 2020 , this body of knowledge was translated into a final, refined version of the kit, which was then industrially produced and is now freely available in the two cities.

To achieve the goal of engaging a broader public, it was necessary to initiate a collaborative process with the different actors in the project. First, the researchers, who had backgrounds in different disciplinary domains and some of whom were practitioners. Second, with the local authorities and heritage holders. And finally, the sources of the knowledge that we wished to intercept: the ordinary people who experience this cultural heritage site. From the disciplinary point of view, the complexity of the heritage assets made it desirable to involve a diverse range of fields: from geography to soundscapes, from autobiography to outdoor education, from landscape architecture to video-making, from art history to contemporary art production, from art education to bodily pedagogy. The research team intentionally invited experts without a background in cultural heritage with a view to applying their specific skills to the interpretation of cultural heritage.

Regarding the educational approach to be implemented, the research group drew on the field of informal education [2] and active methodologies. With the adolescent participants, the team applied cooperative learning [3] and peer education [4] methods to trigger metacognitive processes [5]. This represented a paradigm shift with respect to the process of heritage exposure: from a lecture-style narrative by an expert, to re-source-based education about cultural objects. Scientifically validated sources were selected with a view to eliciting a process of interpretation by the different audiences.

Members of the public, researchers, practitioners and institutions collaborated on constructing a body of knowledge to be made available to further audiences. 


\section{METHODOLOGY}

During the first phase of the study (Phase1), we reviewed the quantitative tools currently used by international organizations and research groups in the field of urban planning and quality of life. Our main goal was to identify the dimensions that could compose a reliable picture of people's subjective representations of a specific place. The conceptual model on which the survey questions were based included dimensions drawn from the urban prosperity index [6], and the City Reputation Index [7]. The dimensions were initially operationalized via 60 manifest indicators designed to access individual impressions, opinions, and representations of the places under investigation. The first phase also involved getting privileged respondents with backgrounds in the social sciences (pedagogy, psychology, geography) to carry out a preliminary evaluation of the pool of empirical items in terms of their salience, comprehensibility, and appropriateness with respect to the context. The output of the first phase was an initial set of 51 items constituting the quantitative tool. The items mapped different features of a place, and respondents were asked to rate their level of agreement (from $1=I$ totally disagree to $7=\mid$ totally agree) with each statement. During the second phase of the study (Phase2), the questionnaire was administered to a large sample of participants (residents, visitors, students, and tourists) from three different settings: Milan, Mantua, and Sabbioneta. In keeping with the dimensionality of the questionnaire, the resulting sample was composed of about 600 participants, divided as follows: Milan $(n=306)$, Mantua $(n=132)$, and Sabbioneta $(n=154)$. The data collected were analyzed using uni- and multi-variate techniques with a view to developing psychometrically robust, self-report questionnaires [8; 9]. Specifically, we assessed the scores for the different questionnaire items in relation to the prerequisites for parametric statistical analysis (normality of distribution and missing data rates) and then subjected them to exploratory and confirmatory factor analysis. We identified two models for measuring subjective representations of places visited: one related to predominantly internal factors (identification, social relations, individual quality of life) and one related to predominantly externalenvironmental factors (green spaces, traffic, mobility). The outcome of Phase 2 was a statistically robust measurement model with the capacity to collect valid and reliable empirical information. The final measurement model consisted of 35 empirical indicators saturating 11 underlying latent dimensions: livability, attachment, tranquility, distinctiveness, welcoming, historical heritage, safety, relaxation, connections, traffic, and food. For the purposes of the present study, we only analyze the data collected in Mantua and Sabbioneta, focusing specifically on the differences between tourists and residents in the two cities.

\section{RESULTS}

With regard to Mantua, the highest rated dimensions for residents were: food (5.56), historical heritage (5.64), traffic conditions (5.09), and green spaces (5.01). The highest rated dimensions for tourists were: historical heritage (6.15), personal fit (6.01), openness (5.85), and social aspects (5.89). In terms of the differences between the two cohorts of participants (residents vs. tourists), in general, tourists tended to score higher on all dimensions of the questionnaire. The more significant gap in perceptions concerned openness and social aspects, whereas the most closely "aligned" scores concerned food, traffic conditions, historical heritage, and green spaces. 


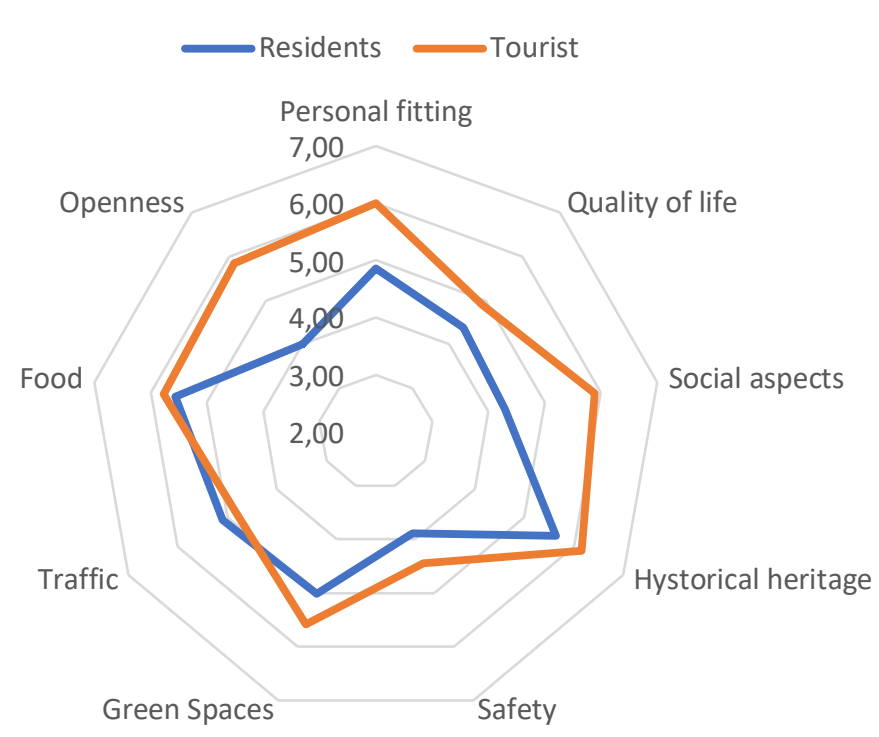

Figure 1. Comparison between residents' and tourists' perceptions of Mantua ( $n=84$; $\min =1, \max =7)$.

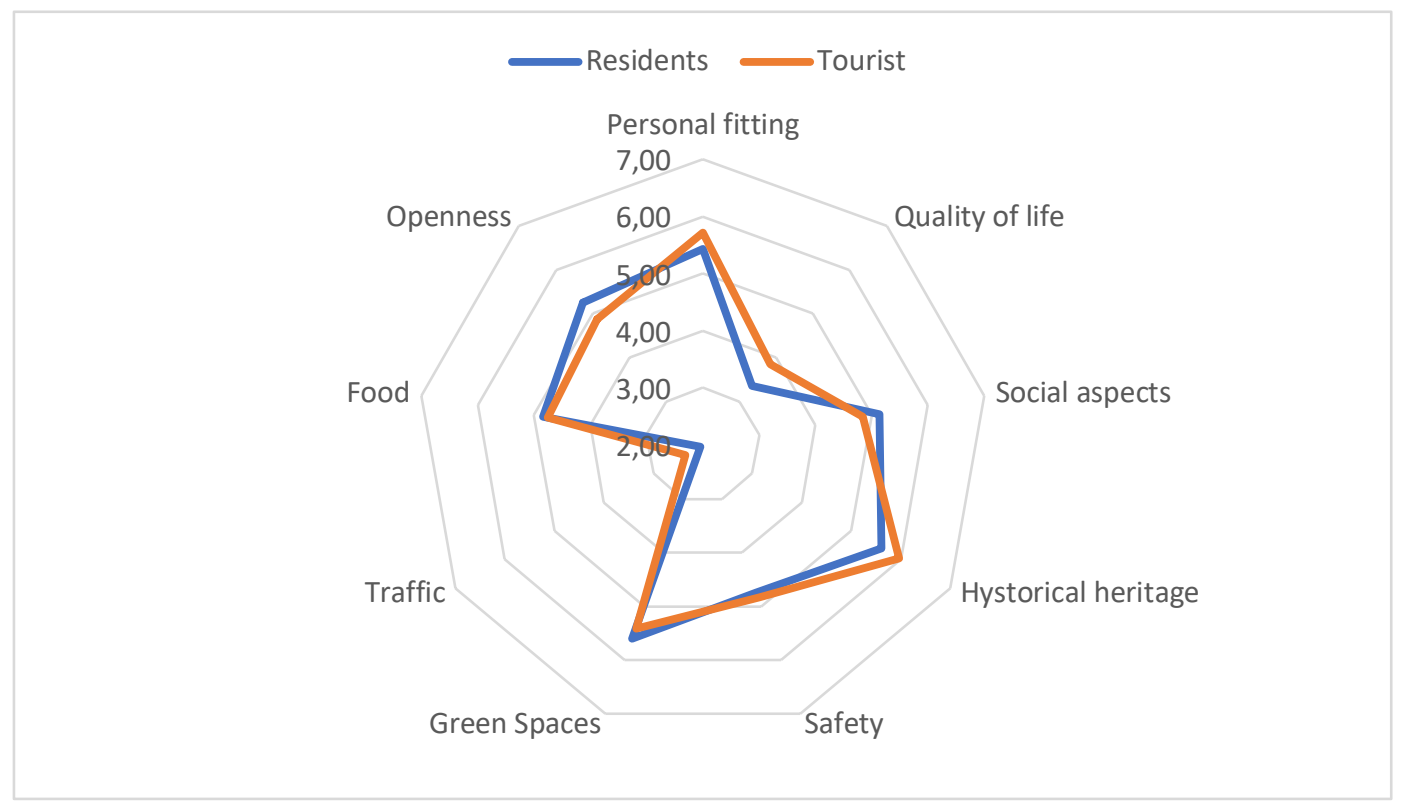

Figure 2. Comparison between residents' and tourists' perceptions of Sabbioneta ( $n=96$; $\min =1, \max =7$ ).

With regard to Sabbioneta, the most positively rated dimensions for residents were: historical heritage (5.61), green spaces (5.60), openness (5.09) and personal fit (5.01). The most highly rated dimensions for tourists were: historical heritage (5.96), personal fit (5.72), openness (4.87) and green spaces (5.42). In terms of differences between the two cohorts (residents vs. tourists), in general their respective scores were quite closely aligned, suggesting broadly similar perceptions of the city.

\section{REFLECTING ON THE CITIES AND FUTURE DIRECTIONS OF INQUIRY}

Analysis of the questionnaire data revealed a slight gap between tourists and citizens in terms of their opinion of the two heritage cities; tourists seemed to be more positive, while residents were more inclined to flag aspects that could be improved. In order to further explore the differences between these two categories, in relation to Mantua and Sabbioneta, we used other instruments such as interviews with privileged informants and ordinary people encountered at public events (markets, exhibitions, ...), who had volunteered to participate in the research. Through these interviews, we set out to investigate the more private and personal side of respondents' relationship with the city, for example by asking them to 
tell us about a memory linked with one of these places, or a specific aspect that they would choose to highlight to somebody who had never visited this city [ 9]. In addition, given that the self-report questionnaires were administered in person and not online, the researchers' conversational exchanges with respondents were a further source of information that shed light on people's personal, emotional, and sometimes conflictual relationships with these specific places. Another task administered involved asking participants to draw a map of the city $[10,11]$ and to mark their favourite places or the places with the strongest role in their personal lives. Using multiple research instruments enabled us to tap into what the ancients referred to as the genius loci: "A place is a space with a distinctive character. Since ancient times, the genius loci, the spirit of the place, has been viewed as the concrete reality that man faces in daily life." [12]. This distinctive character, or personality of the places under study was reconstructed by composing the individual accounts collected into a mosaic, representing multiple points of view expressed by participants of different ages, occupations, personal histories, which nonetheless added up to form a meaningful identity. Within an overall story, individual stories intertwined, contributing to weave a fabric, the weft and the warp. However, a hiatus sometimes appeared in this collection of stories, in the sense that they seemed to be confined to certain generations and not to have been passed on to the younger generations. A board game research instrument was used with the high school students on work experience to elicit their memories, knowledge and appreciation of different parts of the city they lived in, while also getting them to interact with privileged informants who, rather than delivering a lesson about the city, shared an everyday life narrative about these same areas. This exercise in re-appropriating the city involved two other key components: searching for photographs on collectively chosen themes including: water, textures, colours; and creating brief fanzines with a view to making visible selected narratives of the two cities. The outcome was ever-deeper contact with the city and its heritage. A subsequent step entailed developing a toolkit targeting both residents and tourists, that was designed to foster curiosity and discovery, outside of the more traditional routes linked to hit and run tourism, which only favours certain pre-defined places. In the opinion of some scholars, tourism in some art cities risks leading, after long periods of growth, which appear to be positive, towards a mode of fast consumption that risks compromising the city's intrinsic identity: "Although the arrival of new [...] tourists can further increase demand, art cities are beginning to be exposed to a series of risks. The most frequent is that of bearing the costs rather than the benefits of the presence of visitors who do not reside in and, therefore, do not spend in the city; this can lead to an increase in prices, a deterioration in the quality of services, and a loss of attractiveness of the tourist centre." [13]. The present research was aimed at identifying a different way of getting to know these cities, making a journey of reappropriation, away from the routes characterized by rapid tourism, while focusing on details, seeking out stories, and tapping into ancient as well as contemporary features. Based on the questionnaire data, the personal accounts of interviewees, and the reflections of the participating secondary school students, a landscape consumption kit was created, consisting of a set of concrete objects, such as photographs of details, interactive maps, a travel notebook, a themed board game. This material was intended to mediate between users and the cities, fostering interest and prompting discovery. A tool to encourage reflection and reduce the risk of losing sight of the value of these heritage sites. 


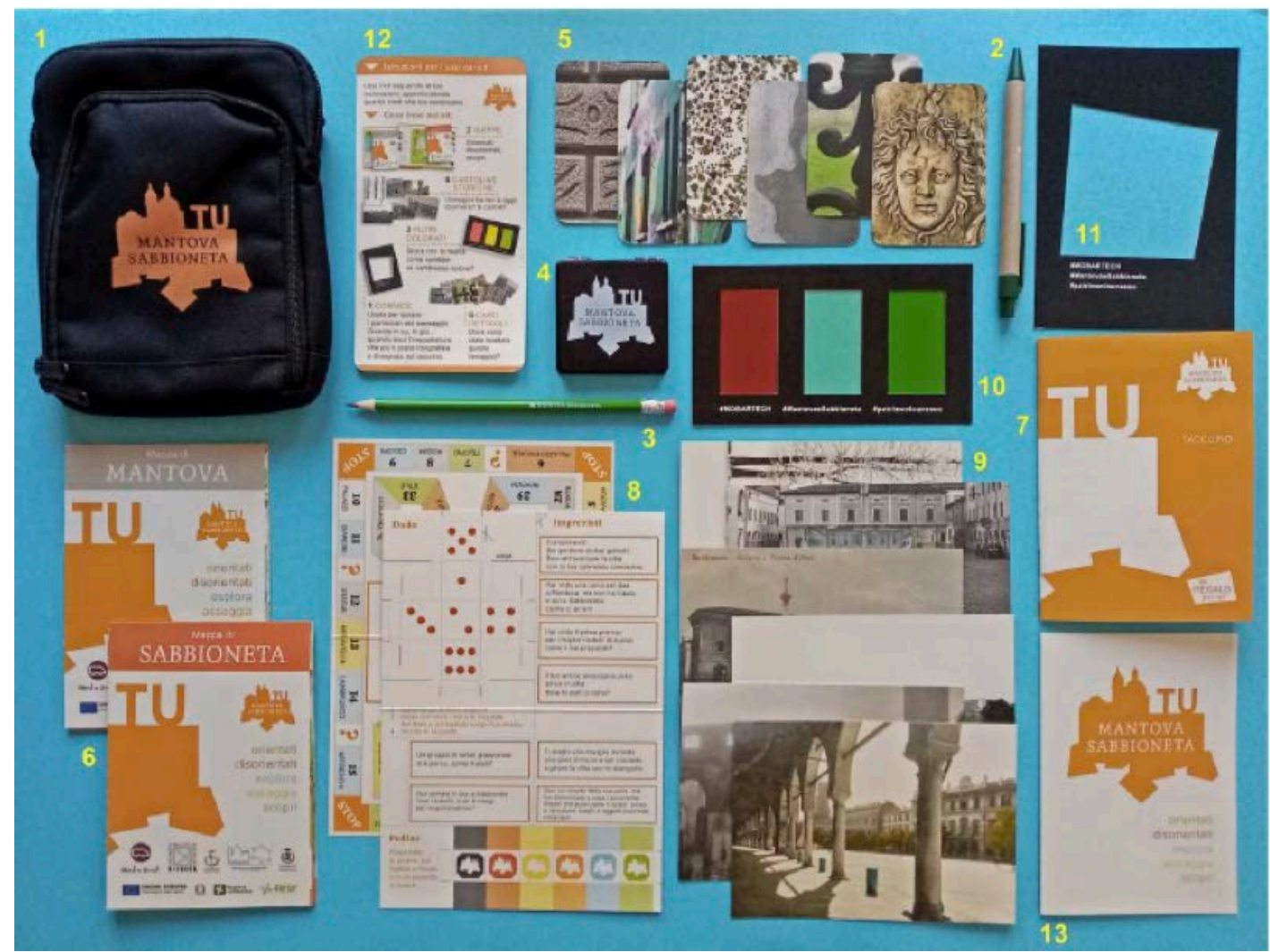

Figure 3. Some of the items contained in the kit.

\section{CONCLUSIONS}

This paper presented a research journey carried out at a single world heritage site comprising the two cities of Mantua and Sabbioneta. The aim of the study was to listen to the voices of the people who live in these cities or who visit them even for a short time, as tourists. Based on their reflections, a set of materials were created with a view to eliciting greater and more focused interest in these places, and fostering more mindful inquiry into their heritage assets and stories. The instruments devised ad hoc for the project were thoroughly piloted and tested, with a view to making them as robust as possible. The final output was a toolkit designed to foster appreciation of the heritage of the two cities. The research process implemented enabled us to verify the key importance in heritage research of working collaboratively with those who experience heritage assets in their everyday lives, becoming the ear that listens and the eye that captures the small details, and discovering how places are alive thanks to the people who populate them, who modify them, and who endow them with meaning. Emphasizing the value of heritage sites makes sense if it includes maintaining constant, lively contact with the people who live there. 

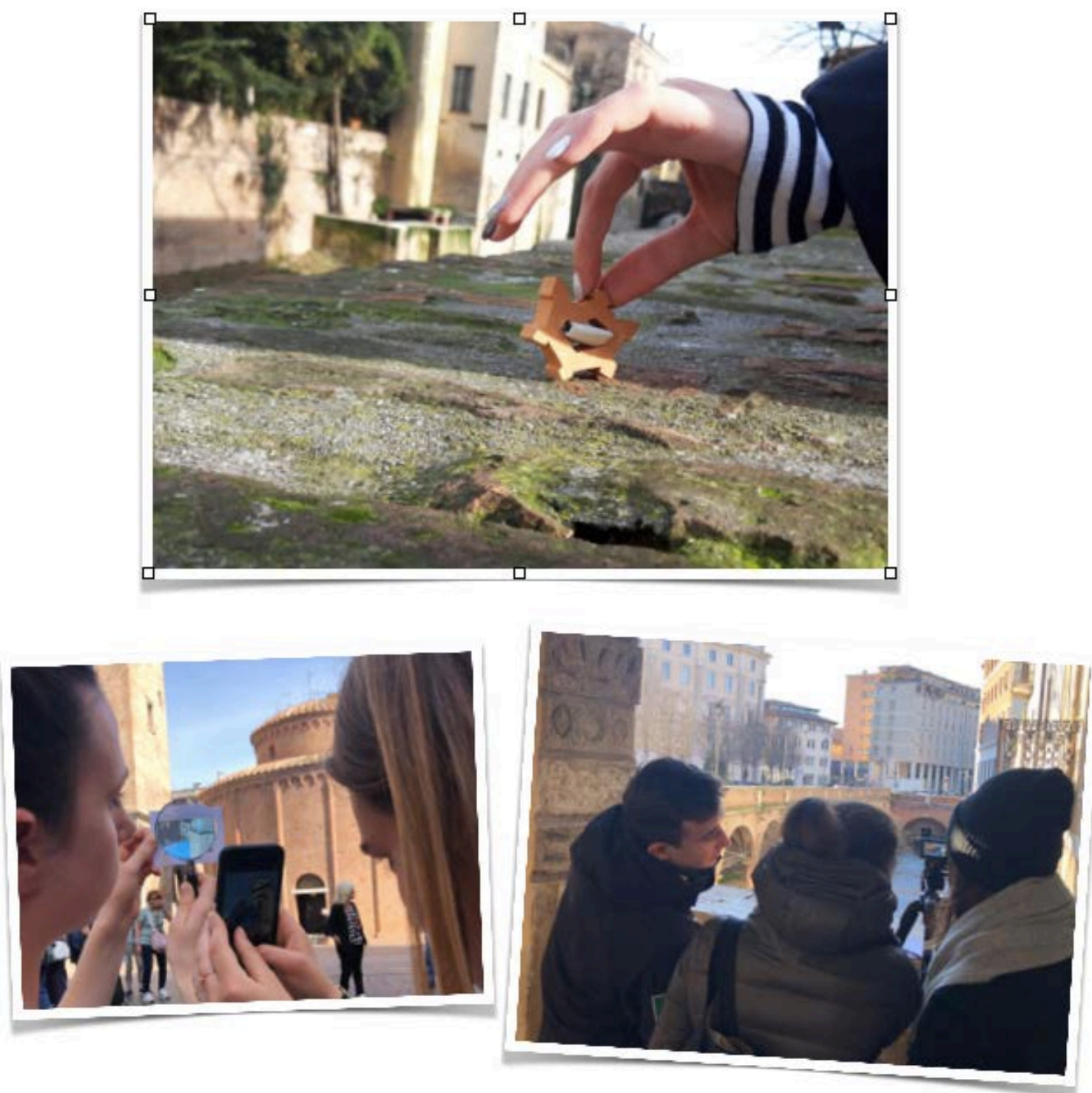

Figure 4. Co-creations Actividies.

\section{REFERENCES}

[1] A. De Nicola, F. Zuccoli (2021), "Heritage and Community. Two Experiences of Heritage Education, a Research to Create a Sense of Community Belonging". In Onsès-Segarra, J. \& HernándezHernández, F. (Eds.). Educational Research: (Re)connecting Communities. Proceedings of ECER 2020. NW 29. Research on Arts Education. pp.51-55. Barcelona: University of Barcelona - Dipòsit Digital, 2021.

[2] S. Tramma, Che cos'è l'educazione informale. Roma: Carocci Editore, 2009.

[3] Johnson, D. W., Johnson R.T., "Effects of Co- Operative, and Individualistic learning Experiences on Social Development", pp.323-9, in Exceptional Children, 49, 4, 1983.

[4] G. Di Cesare, R. Giammetta, L'adolescenza come risorsa. Una guida operativa alla peer education. Roma: Carocci, 2011.

[5] O. Albanese, P. A. Doudin \& D. Martin, Metacognizione e educazione. Milano: Franco Angeli, 2002.

[6] Habitat, U. N., State of the world's cities 2012/2013: Prosperity of cities. New York: Routledge, 2013. 
[7] M. Bonaiuto, S. Ariccio, S. De Dominicis, F. Fornara, E. Molinario, R. Troffa, \& H. Wang, "City Reputation Indicators (CRIs): measuring inhabitants' city representation/Indicadores de Reputación Urbana: midiendo la representación de una ciudad en sus habitantes," Psyecology, vol. 10, no. 1, pp. 31-87, 2019.

[8] C. Cavalera, A. Pepe, V. Zurloni, B. Diana, \& O. Realdon, "A short version of the State Shame and Guilt Scale (SSGS-8)", TPM-Testing, Psychometrics, Methodology in Applied Psychology, vol. 24, no. 1, pp. 99-106, 2017.

[9] D. Demetrio, E. Biffi, E. (Eds.), Per una pedagogia e una didattica della scrittura. Milano: Unicopli, 2007.

[10] N. Pezzoni, La città sradicata. L'idea di città attraverso lo sguardo e il segno dell'altro. Milano: O barra O edizioni, 2020.

[11] H. Cann, Disegnare mappe a mano. Modena: Logo edizioni, 2017.

[12] C. Norberg-Schulz, Genius Loci. Paesaggio, Ambiente, Architettura. Milano: Electa, 2011, p.5.

[13] M. Colleoni, F. Guerisoli, F. La città attraente. Luoghi urbani e arte contemporanea. Milano: Egea, 2014, p.102. 